\title{
Mycobacterium tuberculosis 19-kDa lipoprotein induces Toll-like receptor 2-dependent peroxisome proliferator-activated receptor $\gamma$ expression and promotes inflammatory responses in human macrophages
}

\author{
LI LIU, JINCHENG LIU, GUOQIANG NIU, QIANHONG XU and QILIANG CHEN \\ Department of Tuberculosis Medicine, The Tuberculosis Prevention and Care Hospital of Shaanxi Province,
} Xi'an, Shaanxi 710100, P.R. China

Received October 29, 2013; Accepted May 15, 2014

DOI: $10.3892 / \mathrm{mmr} .2014 .3070$

\begin{abstract}
Mycobacterium tuberculosis (M.tb) enhances its survival in macrophages by suppressing immune responses, in part through its complex cell wall structures. M.tb 19-kDa lipoprotein (P19), a component of the complex cell wall structures of M.tb, is a Toll-like receptor (TLR) agonist, and may induce immune responses through TLR2. Furthermore, the activation of peroxisome proliferator-activated receptor $\gamma(\operatorname{PPAR} \gamma)$ is also involved in M.tb-induced immune responses in macrophages. In the present study, specific agonists/antagonists and siRNA were used to investigate the role of PPAR $\gamma$ in P19-induced immune responses in human macrophages, including TLR2 activation, p38 phosphorylation and cytokine production. In the present study, PPAR $\gamma$ expression, p38 phosphorylation and cytokine production were upregulated following M.tb H37Rv infection or P19 treatment. By pretreating macrophages with a specific PPAR $\gamma$ agonist or antagonist, it was demonstrated that phosphorylation and IL-6 production are modulated in macrophages by PPAR $\gamma$ activity. Following TLR 2 knockdown in macrophages, the expression of PPAR $\gamma$ was significantly decreased in the presence or absence of P19 treatment. Furthermore, p38 phosphorylation and cytokine production were significantly reduced in TLR2 knockdown macrophages following P19 treatment. It was demonstrated in the current study that PPAR $\gamma$ was induced and activated by M.tb infection and that P19-induced PPAR $\gamma$ expression, p38 phosphorylation and cytokine production in macrophages are dependent on TLR2. These findings suggest a role for PPAR $\gamma$ and TLR2 in P19-induced p38 phosphorylation and cytokine production, thereby potentially influencing M.tb pathogenesis.
\end{abstract}

Correspondence to: Dr Jincheng Liu, Department of Tuberculosis Medicine, The Tuberculosis Prevention and Care Hospital of Shaanxi Province, 1 Taiyi Gong Shangwan, Xi'an, Shaanxi 710100, P.R. China

E-mail: jincheng_liu902@126.com

Key words: Mycobacterium tuberculosis, macrophages, peroxisome proliferator-activated receptor $\gamma$, Toll-like receptor 2

\section{Introduction}

Tuberculosis is a common infectious disease usually caused by Mycobacterium tuberculosis (M.tb) (1). Tuberculosis most regularly affects the lungs, but can potentially affect almost any other body organ. M.tb is spread when individuals with active M.tb infection cough, sneeze, or otherwise transmit respiratory fluids through the air (2). The majority of M.tb infections are asymptomatic and latent, but approximately one in ten latent infections eventually progresses to active tuberculosis which, if left untreated, is fatal in $>50 \%$ of cases.

Peroxisome proliferator-activated receptor (PPAR), a member of the lipid-activated nuclear receptor family, is a key transcriptional regulator of cell differentiation, inflammation, and lipid metabolism in macrophages and dendritic cells (3). PPARs are expressed in leukocytes, including macrophages, dendritic cells, $\mathrm{T}$ cells and B cells, and a role for these receptors in inflammation and immunoregulation has previously been proposed $(4,5)$. There are three types of human PPARs: $\alpha, \gamma$, and $\beta / \delta$, and each type is the product of a different gene (6). PPAR $\gamma$, a nuclear receptor superfamily member, is a transcriptional factor that regulates inflammation and is highly expressed in alternatively activated alveolar macrophages and macrophage-derived foam cells, both of which are closely associated with the pathogenesis of tuberculosis (7). A previous study demonstrated that PPAR $\gamma$ is involved in lipid body biogenesis, revealing a cross-talk between the innate immune receptor Toll-like receptor 2 (TLR2) and the lipid-activated nuclear receptor PPAR $\gamma$ that coordinates lipid metabolism and inflammation in the Bacillus Calmette-Guérin (BCG)-infected macrophages, thereby potentially altering mycobacterial pathogenesis (8). Although it is well established that PPAR $\gamma$ acts as a master regulator in lipid metabolism and inflammation, the involvement of PPAR $\gamma$ in the immune response of macrophages to intracellular pathogen infection remains to be elucidated.

Tumor necrosis factor $\alpha$ (TNF- $\alpha)$ is crucial in establishing and maintaining the inflammatory response against infections (9). The blockage of TNF- $\alpha$ has marked effects on the progression of tuberculosis in experimental models. For example, neutralization of TNF- $\alpha$ in a murine model has been demonstrated to lead to tuberculosis aggravation or 
reactivation (10). Furthermore, increased levels of TNF- $\alpha$ are frequently detected in the culture supernatants of peripheral blood mononucleated cells from patients with pulmonary tuberculosis stimulated with mycobacterial antigens $(11,12)$. Similar to TNF- $\alpha$, IL-6 is involved in chronic inflammatory diseases (13). IL-6-deficient (IL-6 $6^{-/}$) mice are resistant to the induction of various experimental inflammatory diseases (14). The mitogen-activated protein kinase (MAPK) pathway is important for immune response and mycobacterial pathogenesis (15-17), and MAPK family members include extracellular signal-regulated kinase, p38 MAPK (p38), and stress-activated protein kinase/c-Jun N-terminal kinase (18). It has been reported that $\mathrm{p} 38$ was activated in monocytes following M.tb infection (19). The involvement of TLR2 in the M.tb infection is well-defined, as patients with TLR2 polymorphisms exhibit increased susceptibility to M.tb infection, whereas TLR $2^{-/-}$mice are unable to mount optimal immune responses against mycobacteria (20). However, potential additional signaling pathways involved in M.tb-induced molecular regulation are unknown.

The aim of the current study was to investigate the role of PPAR $\gamma$ in P19-induced immune responses, including TLR2 activation, p38 phosphorylation and cytokine production.

\section{Materials and methods}

Reagents and antibodies. PPAR $\gamma$ agonist BRL49653, antagonist GW-9662 and fetal bovine serum (FBS) were purchased from Cayman Chemical Co. (Ann Arbor, MI, USA). Cell culture reagents, medium, L-glutamine and antibiotics were obtained from Gibco-BRL (Rockville, MD, USA). Monoclonal antibodies (all produced from immunized rabbits) against PPAR $\gamma$, phospho-p38, MAPK (Thr180/Tyr182), total p38, TLR2 and GAPDH were purchased from Cell Signaling Technology, Inc. (Danvers, MA, USA). TLR2 small interfering (si)RNA and control siRNA (fluorescein isothiocyanate-conjugated) were purchased from Santa Cruz Biotechnology, Inc. (Santa Cruz, CA, USA).

Bacterial strains and P19 isolation. Lyophilized M.tb H37Rv (ATCC 25618) and Mycobacterium smegmatis (M. smegmatis; ATCC 700084) were obtained from American Type Culture Collection (ATCC; Manassas, VA, USA), reconstituted and used as described previously (21). The concentration of bacteria was determined by counting in a Petroff-Hausser chamber (Hede Biotechnology, Beijing, China). Bacteria prepared in this manner are $\geq 90 \%$ viable as assessed by colony forming unit assays.

Purified M.tb 19-kDa lipoprotein (P19) was obtained as described previously (22). In brief, cell-wall fractions were obtained by sonication of suspended M.tb H37Rv at $20 \mathrm{kHz}$ in iced water ( 5 cycles for 5 min each). Protein $(40 \mu \mathrm{g})$ were mixed with a reducing sample buffer $(0.05 \mathrm{mM}$ EDTA, $0.1 \%$ SDS, $1 \%$ glycerol, $10 \%$ 2-mercaptoethanol, and $0.5 \mathrm{mM} / \mathrm{ml}$ Tris- $\mathrm{HCl} \mathrm{pH} 6.8$ ), heated for $5 \mathrm{~min}$ at $95^{\circ} \mathrm{C}$ and loaded onto $12 \%$ SDS-PAGE gels. Following electrophoresis, proteins were transferred to a polyvinylidene fluoride (PVDF) membrane and stained with Ponceau S red (Energy Chemicals, Shanghai, China) to identify the $19 \mathrm{kDa}$ band; the identity of this band was confirmed in parallel blots with the IT-19 monoclonal antibody. The band was then excised, solubilized in dimethylsulfoxide
(DMSO) and precipitated with carbonate/bicarbonate sodium buffer (0.05 M, pH 9.6). The pellet was rinsed three times with phosphate-buffered saline (PBS; pH 7.4) and stored at $-20^{\circ} \mathrm{C}$. The concentration of the protein was measured with the Bradford Protein Assay kit (Bio-Rad, Hercules, CA, USA).

Cell culture and mycobacterial infection. The WBC 264-9C macrophage cell line (HB-8902; ATCC) was cultivated in cultured in RPMI-1640 medium supplemented with $15 \%$ FBS, 10 mM HEPES [4-(2-hydroxyethyl)-1-piperazineethanesulfonic acid], $2 \mathrm{mM}$ L-glutamine, and $50 \mu \mathrm{g} / \mathrm{ml}$ gentamicin at $37^{\circ} \mathrm{C}$ in a humidified incubator containing $5 \% \mathrm{CO}_{2}$. For P19 stimulation or infection with M.tb H37Rv or M. smegmatis, WBC 264-9C cells were placed in 12-well culture plates with glass coverslips at a density of $5 \times 10^{5}$ cells $/ \mathrm{ml}$ for $24 \mathrm{~h}$. Cells were then washed and incubated for an additional $18 \mathrm{~h}$ in the medium with $0.1 \%$ FBS. The macrophage monolayers in the tissue culture plates were washed with prewarmed RPMI-1640 medium and replaced with $1 \mathrm{ml}$ RPMI-1640 medium containing $10 \mathrm{mM}$ HEPES and $0.4 \%$ human serum albumin, and viable M.tb H37Rv or M. smegmatis at a multiplicity of infection of 1:10 macrophage/bacteria, or treated with $5 \mu \mathrm{g} / \mathrm{ml}$ $\mathrm{P} 19$, and incubated at $37^{\circ} \mathrm{C}$ for various time periods prior to analysis. Alternatively, cells were pretreated with BRL49653 (5 $\mu \mathrm{M}), \mathrm{GW}-9662(1 \mu \mathrm{M})$ or $0.01 \%$ DMSO (as vehicle-control) at $37^{\circ} \mathrm{C}$ for $30 \mathrm{~min}$ prior to bacterial infection. The cells and cell-free supernatants were collected and stored at $-20^{\circ} \mathrm{C}$ for subsequent assays. Cell viability was assessed by a trypan blue (Energy Chemicals) exclusion method at the end of each experiment (viability of $\geq 90 \%$ was required).

TLR2 siRNA transfection. To silence the expression of TLR2, macrophages were transfected with the TLR2 siRNA. The siRNA transfection was performed according to the manufacturer's instructions. In brief, WBC 264-9C macrophages were incubated in the siRNA Transfection medium (Santa Cruz Biotechnology, Inc.) at a density of $2 \times 10^{5}$ cells/well in 12 -well cell culture plates, followed by the addition of the TLR2 siRNA or negative control siRNA, and incubated at room temperature for $30 \mathrm{~min}$. A transfection efficiency of $>95 \%$ was demonstrated by flow cytometry (FACS Calibur, Becton Dickinson, Franklin Lakes, NJ, USA). Following transfection, the TLR2 expression was analyzed by reverse transcription (RT)-quantitative polymerase chain reaction (qPCR) and western blot analysis. The cytokine expression levels in the supernatant of the transfected macrophages were measured by ELISA.

Western blot analysis. The macrophages were rinsed with prewarmed PBS, and lysed in an ice-cold extraction buffer (50 mM Tris, pH 7.5; $150 \mathrm{mM} \mathrm{NaCl;10 \%} \mathrm{glycerol;} 1 \mathrm{mM}$ EDTA; 1 mM EGTA; 1\% NP-40; 1 mM dithiothreitol; and protease inhibitor cocktail (Roche, Basel, Switzerland). The homogenate was incubated on ice for $20 \mathrm{~min}$, then centrifuged at $13,000 \mathrm{x}$ g for $20 \mathrm{~min}$ at $4^{\circ} \mathrm{C}$. The supernatant was collected, and the concentration of the protein in the supernatant was determined using the Bradford Protein Assay kit. The whole cell lysates from the macrophages were subjected to $12 \%$ SDS-PAGE, and subsequently blotted onto a PVDF membrane. The membrane was incubated with the antibodies of interest. 
GAPDH was used as an internal control. The quantitation of protein bands was performed using the Quantity One software (Bio-Rad, Hercules, CA, USA).

$R T$ - $q P C R$. Total RNA from the macrophages was extracted using an RNAiso Plus kit (Takara, Dalian, China) according to the manufacturer's instructions. The extracted total RNA was quantified by absorbance at $280 \mathrm{~nm}$ using a NanoDrop 2000c Spectrophotometer (Thermo Fisher Scientific, Waltham, MA, USA). The mRNA in the total RNA was reverse transcribed to complementary DNA using a PrimeScript RT Reagents kit (Takara). qPCR was performed in the iCycler iQ5 (Bio-Rad) using SYBR Premix Ex Taq II (Takara) with the following conditions: $30 \mathrm{sec}$ at $95^{\circ} \mathrm{C}, 40$ cycles of $5 \mathrm{sec}$ at $95^{\circ} \mathrm{C}$, and $30 \mathrm{sec}$ at $60^{\circ} \mathrm{C}$. The mRNA expression levels, which were normalized against GAPDH, were calculated and expressed as $2^{-\triangle \Delta C T}$. The primers used for qPCR were as follows: PPAR $\gamma$ : F 5'-CATTCTGGCCCACCAACTTTGG-3', and R 5'-TGG AGATGCAGGCTCCACTTTG-3' (229 bp); TRL2: F 5'-AAG AGGAAGCCCAAGAAAGC-3', and R 5'-CAATGG GAATCCTGCTCACT-3' (80 bp); GAPDH: F 5'-ATGGGG AAGGTGAAGGTCG-3', and R 5'-GGGGTCATT GATGGCAACAA-3' (156 bp).

Cytokine assays. Following infection with M.tb H37Rv or M.smegmatis, or treatment with P19, the levels of the cytokines (IL-6 and TNF- $\alpha$ ) from the supernatant of the macrophages were measured with ELISA kits (R\&D Systems, Minneapolis, MN, USA) according to the manufacturer's instructions.

Statistical analysis. All data in the present study were analyzed by the statistics package SPSS, version 13.0 (SPSS, Inc., Chicago, IL, USA). All data are expressed as the mean \pm standard error. A direct comparison between two groups was conducted with the Student's non-paired t-test, and analysis of variance (ANOVA) with Tukey's post-hoc tests was used to compare the means of three or more groups. $\mathrm{P}<0.05$ was considered to represent a statistically significant difference.

\section{Results}

PPAR $\mathrm{r}$ expression, p38 phosphorylation and cytokine production were upregulated following M.tb H37Rv infection or P19 treatment. To investigate the effect of P19 treatment on PPAR $\gamma$ expression, p38 phosphorylation and cytokine production, human macrophages were incubated with $5 \mu \mathrm{g} / \mathrm{ml}$ purified P19 for various time periods (from 0 to 48 h). M.tb H37Rv or M. smegmatis infection were used as controls. The expression of PPAR $\gamma$ was significantly upregulated by M.tb H37Rv infection $\left(\mathrm{F}_{(4,10)}=35.34, \mathrm{P}<0.0001\right)$ and $\mathrm{P} 19$ stimulation $\left(\mathrm{F}_{(4,10)}=19.24\right.$, $\mathrm{P}<0.01$ ) (Fig. 1A). Post hoc analysis revealed that the expression levels of PPAR $\gamma$ were upregulated at $48 \mathrm{~h}$ compared with the levels at $0 \mathrm{~h}$, following M.tb infection $(5.40 \pm 0.40$-fold, $\mathrm{P}<0.0001)$ or $\mathrm{P} 19$ treatment $(4.10 \pm 0.41$-fold, $\mathrm{P}<0.0001)$. M. smegmatis infection did not significantly affect PPAR $\gamma$ levels $\left(\mathrm{F}_{(4,10)}=0.11\right.$, $\mathrm{P}=0.87$ ), as expected. The phosphorylation level of $\mathrm{p} 38$ was expressed as the ratio of phospho-p38 to total p38 (Fig. 1B). ANOVA revealed significant differences in levels of p38 phosphorylation following M.tb H37Rv infection $\left(\mathrm{F}_{(4,10)}=35.34\right.$, $\mathrm{P}<0.0001)$ and following $\mathrm{P} 19$ treatment $\left(\mathrm{F}_{(4,10)}=19.24, \mathrm{P}<0.01\right)$.
Phospho-p38 levels were 3.11 \pm 0.20 -fold ( $\mathrm{P}<0.01$, M.tb H37Rv infection) and 2.50 \pm 0.34 -fold $(\mathrm{P}<0.01, \mathrm{P} 19$ treatment) greater at $48 \mathrm{~h}$ than those at $0 \mathrm{~h}$, whereas p38 phosphorylation was not significantly affected by $M$. smegmatis infection $\left(\mathrm{F}_{(4,10)}=0.11\right.$, $\mathrm{P}=0.87$ ). The levels of IL-6 (Fig. 1C) and TNF- $\alpha$ (Fig. 1D) were also analyzed. Two-way ANOVA revealed significant effects of time $\left(\mathrm{F}_{\text {time }(4,30)}=16.29, \mathrm{P}<0.0001\right)$ and infection/treatment $\left(\mathrm{F}_{\text {infection }(2,30)}=57.64, \mathrm{P}<0.0001\right)$ on IL-6 production, as well as an interaction between them $\left(\mathrm{F}_{\text {interaction }(8,30)}=4.46, \mathrm{P}<0.01\right)$. Similarly, the levels of TNF- $\alpha$ were also significantly affected by time $\left(\mathrm{F}_{\text {time }(4,30)}=25.92, \mathrm{P}<0.0001\right)$ and infection/treatment $\left(\mathrm{F}_{\text {infection }(2,30)}=3.94, \mathrm{P}<0.05\right)$; however, no significant effect of time-infection interaction was detected $\left(\mathrm{F}_{\text {interaction }(8,30)}=2.95\right.$, $\mathrm{P}=0.07)$.

P19-induced p38 phosphorylation and IL-6 production is modulated by PPAR $\gamma$. Since M.tb H37Rv infection and P19 treatment upregulate the expression of PPAR $\gamma$, the involvement of PPAR $\gamma$ in p38 phosphorylation and cytokine production induced by $\mathrm{P} 19$ in macrophages was investigated. As expected, the levels of p38 phosphorylation were significantly elevated following 24-h P19 treatment compared with those in the vehicle control $(\mathrm{P}<0.05$; Fig. 2A). Pretreatment with a specific PPAR $\gamma$ agonist (BRL49653) or antagonist (GW-9662) did not significantly affect p38 phosphorylation compared with that in the vehicle control. P19 treatment combined with GW-9662 pretreatment significantly upregulated p38 phosphorylation $(\mathrm{P}<0.01$ vs. vehicle control). Additionally, the activation of PPAR $\gamma$ by BRL49653 attenuated P19-induced upregulation of p38 phosphorylation $(\mathrm{P}=0.21)$.

Similarly, $24 \mathrm{~h}$ after P19 treatment, the expression levels of IL-6 were significantly elevated $(\mathrm{P}<0.0001$ vs. control; Fig. 2B). The expression levels of IL-6 were not significantly affected by treatment with the PPAR agonist or antagonist alone. However, when compared with P19 alone, treatment with the PPAR $\gamma$ antagonist significantly upregulated the levels of IL-6 production $(\mathrm{P}<0.05)$, while the PPAR $\gamma$ agonist attenuated them $(\mathrm{P}=0.72)$.

P19-induced PPAR $\gamma$ expression, p38 phosphorylation and cytokine production are dependent on TLR2. To confirm the involvement of the TLR2 in P19-induced PPAR $\gamma$ expression and p38 phosphorylation, the expression of PPAR $\gamma, \mathrm{p} 38$, IL-6 and TNF- $\alpha$ were measured in TLR 2 knockdown macrophages (Fig. 3A). Two-way ANOVA revealed a significant effect of TLR2 knockdown $\left(\mathrm{F}_{\mathrm{TLR} 2 \text {-siRnA(1,8) }}=70.4, \mathrm{P}<0.0001\right)$ and $\mathrm{P} 19$ treatment $\left(\mathrm{F}_{\mathrm{P} 19(1,8)}=23.3, \mathrm{P}<0.01\right)$ on PPAR $\gamma$ mRNA expression, as well as an interaction between them $\left(\mathrm{F}_{\text {interaction }(1,8)}=21.8\right.$, $\mathrm{P}<0.01$ ) (Fig. 3B). Tukey's post hoc tests indicated that the levels of PPAR $\gamma$ mRNA were significantly reduced following TLR2 knockdown, regardless of whether P19 treatment is used or not $(\mathrm{P}<0.0001$ vs. control).

With regards to $\mathrm{p} 38$ phosphorylation, significant effects of TLR2 knockdown $\left(\mathrm{F}_{\mathrm{TLR} 2 \text {-siRnA }(1,8)}=7.81, \mathrm{P}<0.05\right)$, $\mathrm{P} 19$ treatment $\left(\mathrm{F}_{\mathrm{P} 19(1,8)}=14.8, \mathrm{P}<0.01\right)$ and interaction factor $\left(\mathrm{F}_{\text {interaction }(1,8)}=5.97, \mathrm{P}<0.05\right)$ were also detected (Fig. 3C). As expected, the levels of phospho-p38 were increased following $\mathrm{P} 19$ treatment $(\mathrm{P}<0.01$ vs. control). In the absence of P19 treatment, no significant difference in the levels of p38 phosphorylation between the TLR2 knockdown 
A

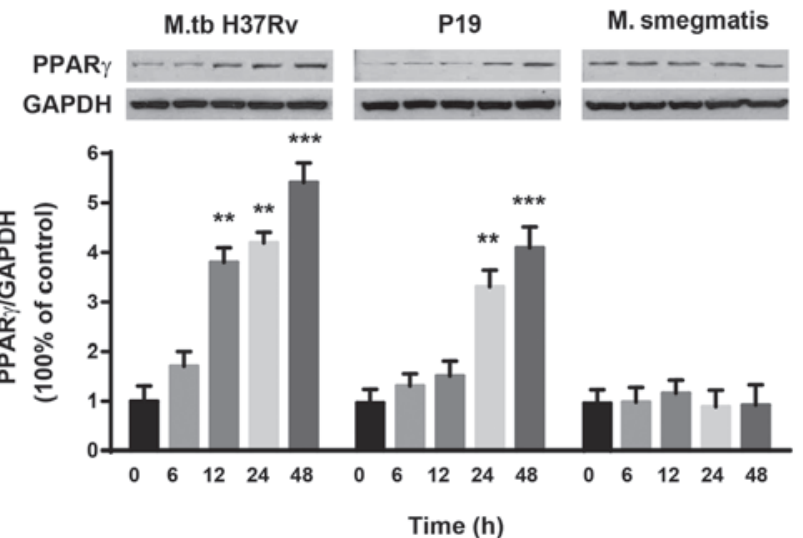

C

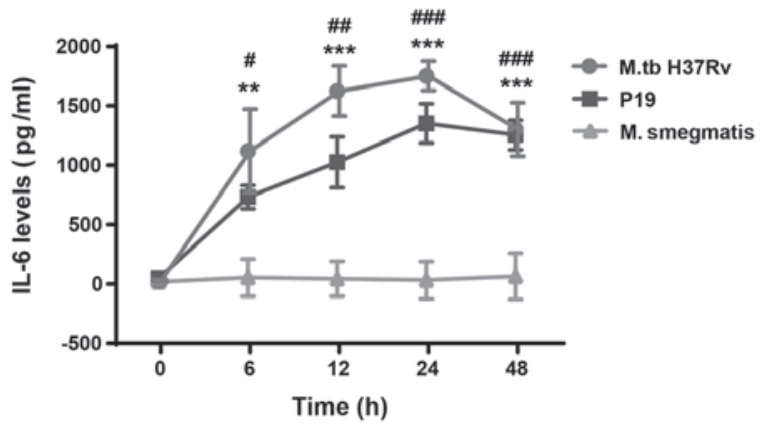

B
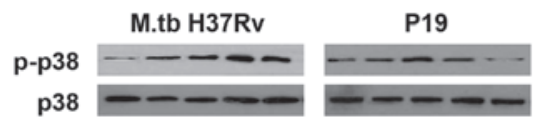

M. smegmatis

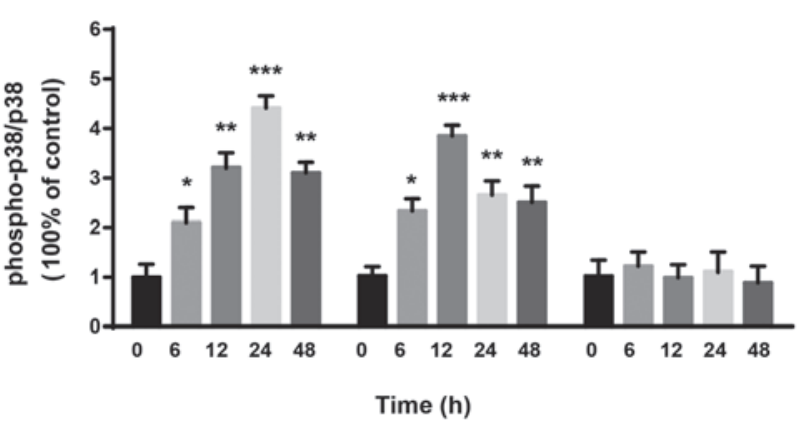

D

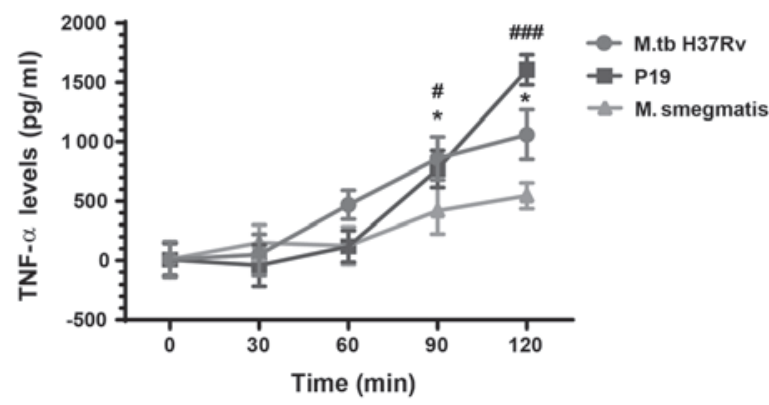

Figure 1 M.tb H37Rv and P19 upregulate the expression of (A) PPAR $\gamma$, (B) p38 phosphorylation, (C) IL-6 and (D) TNF- $\alpha$ in human macrophages. As a control, macrophages were also incubated with $M$. smegmatis. The phosphorylation state of p38 was expressed as the ratio of phospho-p38 to total p38. Data are expressed as the mean \pm standard error $(\mathrm{n}=3)$. For $(\mathrm{A})$ and $(\mathrm{B}):{ }^{*} \mathrm{P}<0.05,{ }^{* * *} \mathrm{P}<0.01,{ }^{* * *} \mathrm{P}<0.0001$ vs. $0 \mathrm{~h}$ within each group. For (C) and (D): ${ }^{*} \mathrm{P}<0.05,{ }^{* * *} \mathrm{P}<0.01$, ${ }^{* * * *} \mathrm{P}<0.0001$, M.tb H37Rv infection vs. M. smegmatis infection at the same time point; ${ }^{*} \mathrm{P}<0.05,{ }^{\# \#} \mathrm{P}<0.01,{ }^{\# \# \#} \mathrm{P}<0.0001, \mathrm{P} 19$ treatment vs. M. smegmatis infection at the same time point. PPAR, peroxisome proliferator-activated receptor; M.tb, Mycobacterium tuberculosis; P19, M.tb 19 kDa lipoprotein; M. smegmatis, Mycobacterium smegmatis; TNF, tumor necrosis factor.

A

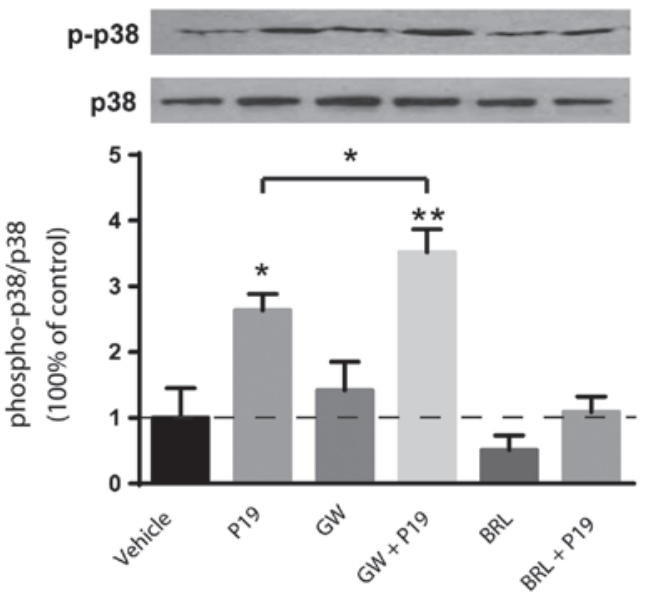

B

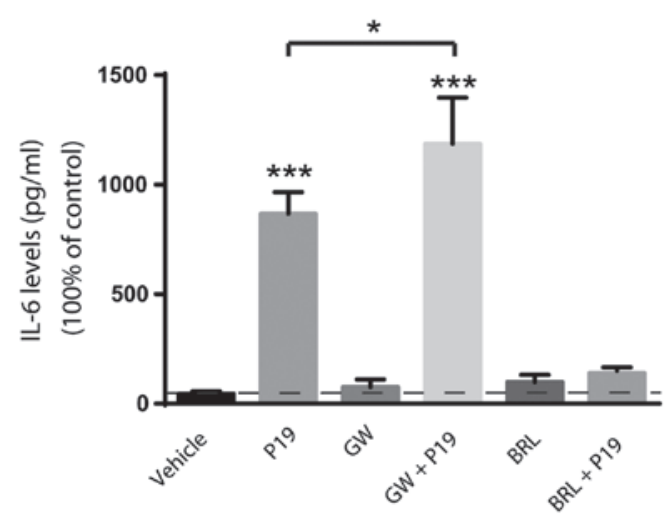

Figure 2 P19-induced p38 phosphorylation is modulated by PPAR $\gamma$. Macrophages were pretreated with the specific PPAR $\gamma$ antagonist GW or agonist BRL alone, or in combination with P19 treatment. (A) The levels of P38 phosphorylation, expressed as the ratio of phospho-p38 to total p38. (B) The levels of IL-6. Data are expressed as the mean \pm standard error $(n=3) .{ }^{*} \mathrm{P}<0.05,{ }^{* * *} \mathrm{P}<0.01,{ }^{* * * *} \mathrm{P}<0.0001$ vs. vehicle control, unless otherwise indicated. $\mathrm{P} 19$, M.tb $19 \mathrm{kDa}$ lipoprotein; PPAR, peroxisome proliferator-activated receptor.

macrophages and negative siRNA-treated macrophages was observed $(\mathrm{P}=0.94)$. However, TLR2 knockdown combined with P19 treatment significantly decreased the levels of $\mathrm{p} 38$ phosphorylation $(\mathrm{P}<0.01)$, compared with levels following P19 treatment without TLR2 knockdown. The levels of IL-6 and TNF- $\alpha$ were also analyzed (Fig. 3D and E, Table I). The results demonstrated that TLR2 knockdown combined with P19 treatment significantly reduced the expression levels of both IL- 6 and TNF- $\alpha$ compared with the levels following P19 treatment without TLR2 knockdown. 
A

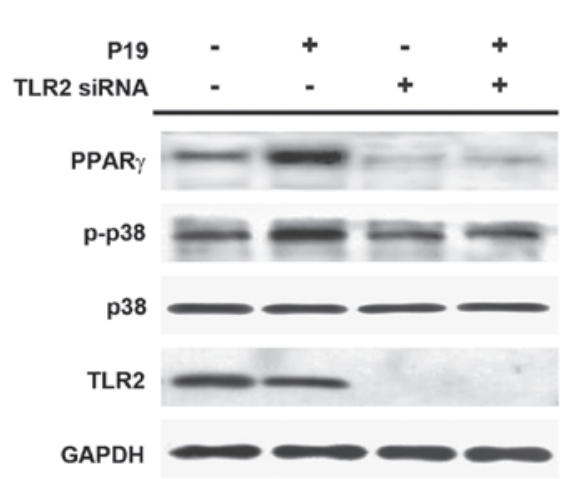

B

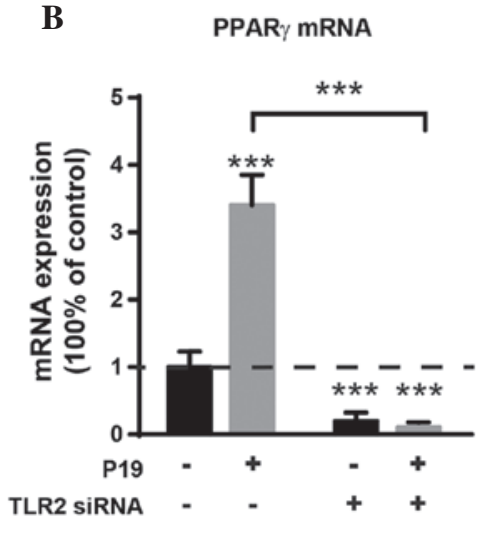

C

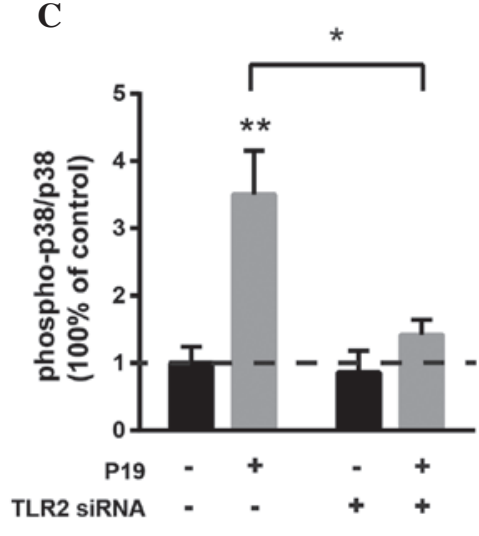

D

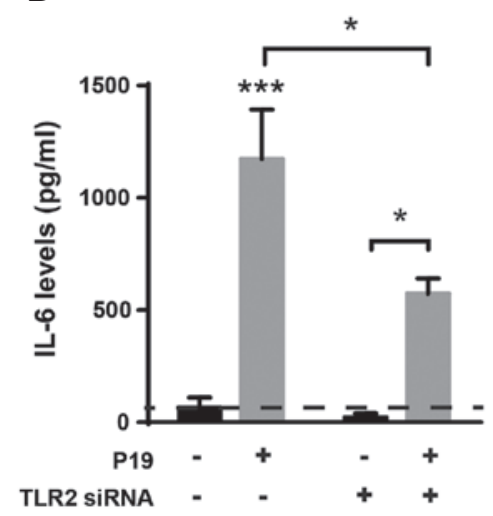

$\mathbf{E}$

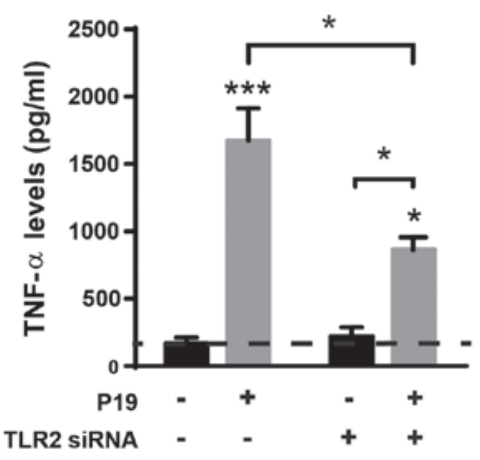

Figure 3. P19-induced PPAR $\gamma$ expression, p38 phosphorylation and cytokine production in macrophages are dependent on TLR2. (A) A representative western blot of PPAR $\gamma$, phospho-p38 and total p38 expression. The expression levels of TLR 2 following TLR 2 knockdown by TLR 2 siRNA were also determined. GAPDH was used as a loading control. (B) PPAR $\gamma$ mRNA expression. (C) The levels of p38 phosphorylation, expressed as the ratio of phospho-p38 to total p38. (D) The levels of IL-6. (E) The levels of TNF- $\alpha$. Data are expressed as the mean \pm standard error $(\mathrm{n}=3)$. ${ }^{*} \mathrm{P}<0.05,{ }^{* * *} \mathrm{P}<0.01,{ }^{* * * *} \mathrm{P}<0.0001$ vs the control unless otherwise indicated. TLR, Toll-like receptor; P19, M.tb 19kDa lipoprotein; PPAR, peroxisome proliferator-activated receptor; si, small interfering; TNF, tumor necrosis factor.

Table I. Statistical results for IL-6 and TNF- $\alpha$ production.

\begin{tabular}{lrr}
\hline Factor & $\mathrm{F}_{(1,8)}$ value & P-value \\
\hline IL-6 levels & & \\
P19 & 49.80 & $<0.0001^{\mathrm{c}}$ \\
TLR2-siRNA & 7.48 & $0.0256^{\mathrm{a}}$ \\
Interaction & 5.62 & $0.0453^{\mathrm{a}}$ \\
TNF- $\alpha$ levels & & \\
P19 & 62.80 & $<0.0001^{\mathrm{c}}$ \\
TLR2-siRNA & 7.74 & $0.0239^{\mathrm{a}}$ \\
Interaction & 10.10 & $0.0131^{\mathrm{a}}$ \\
\hline
\end{tabular}

Levels of IL-6 and TNF- $\alpha$ were analyzed using two-way ANOVA. ${ }^{\mathrm{a}} \mathrm{P}<0.05 ;{ }^{\mathrm{b}} \mathrm{P}<0.01 ;{ }^{\mathrm{c}} \mathrm{P}<0.0001$. TNF, tumor necrosis factor; TLR, Toll-like receptor; si, small interfering; ANOVA, analysis of variance.

\section{Discussion}

Modulation of the host immune response is essential in mycobacterial pathogenesis. M.tb enhances its survival in macrophages by suppressing immune responses, in part through its complex cell wall structures. The purified mycobacterial cell wall lipoprotein P19 is well-defined as a TLR2 agonist (23). PPAR $\gamma$ is a prime candidate for an intracellular molecular switch based on its central role in controlling the inflammatory response in macrophages (24), and although PPAR $\gamma$ has been extensively investigated in other diseases (25), its immunoregulatory role in infectious diseases (particularly tuberculosis) is just beginning to be recognized $(8,26,27)$. In the present study, the expression of PPAR $\gamma$ in human macrophages was enhanced by M.tb H37Rv and P19, but not M. smegmatis. It was also observed that $\mathrm{P} 19$ strongly induces $\mathrm{p} 38$ phosphorylation and cytokine (IL- 6 and TNF- $\alpha$ ) production.

A previous study established that the activation of PPAR $\gamma$ may repress target inflammatory genes, including proinflammatory cytokines and inducible nitric oxide synthase, through ligand-dependent transrepression of NF- $\mathrm{\kappa B}$ target genes (28). de Assis et al (29) demonstrated that the PPAR $\gamma$ agonist BRL49653 potentiates lipid body biogenesis in peritoneal macrophages following oxidized phospholipid stimulation. A similar role for PPAR $\gamma$ in lipid body biogenesis was reported in M. bovis BCG, but not M. smegmatis (8). In the present study, the effect of PPAR $\gamma$ activation during P19 infection was analyzed. It was demonstrated that pretreatment with 
the PPAR $\gamma$ antagonist GW-9662 significantly upregulated P19-induced p38 phosphorylation and IL-6 production. However, pretreatment with the PPAR $\gamma$ agonist BRL49653 or antagonist GW-9662 alone did not affect p38 phosphorylation compared with that of the vehicle control. These results indicate that PPAR $\gamma$ may modulate P19-induced immune response through p38 phosphorylation.

Since TLRs and PPAR $\gamma$ contribute to M.tb-induced immune responses and have been indicated to regulate host susceptibility to pathogens, TLR2 activation involvement in the regulation of PPAR $\gamma$ expression, p38 phosphorylation and cytokine production in the presence of P19 treatment was investigated in the current study. Following TLR2 knockdown in macrophages, the expression of PPAR $\gamma$ was significantly decreased in the presence or absence of P19 treatment. Furthermore, the levels of p38 phosphorylation and cytokine production were significantly reduced in TLR2 knockdown macrophages in the presence of P19 treatment compared with those in non-knockdown macrophages treated with P19. These results demonstrated that PPAR $\gamma$ expression, p38 phosphorylation and cytokine production in human macrophages are associated with TLR2. Results of the present study are consistent with those of previous studies that observed Mycobacterium bovis BCG-induced PPAR $\gamma$ expression, lipid body formation, and $\mathrm{PGE}_{2}$ generation inhibition in TLR2-deficient mice (8).

In conclusion, the findings of the current study demonstrate that the M.tb cell wall component P19 induces PPAR $\gamma$ expression in a TLR2-dependent manner. In the TLR2-dependent signaling pathway, PPAR $\gamma$ acts as a key modulator of inflammation in P19-stimulated macrophages. These findings suggest a role for PPAR $\gamma$ and TLR2 in P19-induced p38 phosphorylation and cytokine production, thereby potentially affecting the M.tb pathogenesis. Future studies in animal models are required to further characterize the role of PPAR $\gamma$ and TLR2 in the pathogenesis of tuberculosis.

\section{References}

1. Kumar V, Abbas AK, Fausto N and Mitchell RN (eds): Robbins Basic Pathology. 8th edition. Saunders Elsevier, Philadelphia, PA, pp516-522, 2007.

2. Konstantinos A: Testing for tuberculosis. Aust Prescr 33: 12-18, 2010.

3. Szatmari I and Nagy L: Nuclear receptor signalling in dendritic cells connects lipids, the genome and immune function. EMBO J 27: 2353-2362, 2008.

4. Szanto A and Nagy L: Retinoids potentiate peroxisome proliferator-activated receptor gamma action in differentiation, gene expression, and lipid metabolic processes in developing myeloid cells. Mol Pharmacol 67: 1935-1943, 2005.

5. Szatmari I, Töröcsik D, Agostini M, et al: PPARgamma regulates the function of human dendritic cells primarily by altering lipid metabolism. Blood 110: 3271-3280, 2007.

6. Braissant O, Foufelle F, Scotto C, Dauça M and Wahli W: Differential expression of peroxisome proliferator-activated receptors (PPARs): tissue distribution of PPAR-alpha, -beta, and -gamma in the adult rat. Endocrinology 137: 354-366, 1996.

7. Rigamonti E, Fontaine C, Lefebvre B, et al: Induction of CXCR2 receptor by peroxisome proliferator-activated receptor gamma in human macrophages. Arterioscler Thromb Vasc Biol 28 932-939, 2008

8. Almeida PE, Silva AR, Maya-Monteiro CM, et al: Mycobacterium bovis bacillus Calmette-Guérin infection induces TLR2-dependent peroxisome proliferator-activated receptor gamma expression and activation: functions in inflammation, lipid metabolism, and pathogenesis. J Immunol 183: 1337-1345, 2009.
9. Bruns H, Meinken C, Schauenberg P, et al: Anti-TNF immunotherapy reduces $\mathrm{CD}^{+} \mathrm{T}$ cell-mediated antimicrobial activity against Mycobacterium tuberculosis in humans. J Clin Invest 119: 1167-1177, 2009

10. Mohan VP, Scanga CA, Yu K, et al: Effects of tumor necrosis factor alpha on host immune response in chronic persistent tuberculosis: possible role for limiting pathology. Infect Immun 69: 1847-1855, 2001

11. Dlugovitzky D, Bay ML, Rateni L, et al: Influence of disease severity on nitrite and cytokine production by peripheral blood mononuclear cells (PBMC) from patients with pulmonary tuberculosis (TB). Clin Exp Immunol 122: 343-349, 2000.

12. Al-Attiyah R,El-Shazly A and Mustafa AS: Comparative analysis of spontaneous and mycobacterial antigen-induced secretion of Th1, Th2 and pro-inflammatory cytokines by peripheral blood mononuclear cells of tuberculosis patients. Scand J Immunol 75: 623-632, 2012.

13. Jones SA, Scheller J and Rose-John S: Therapeutic strategies for the clinical blockade of IL-6/gp130 signaling. J Clin Invest 121: 3375-3383, 2011.

14. Silva LC, Ortigosa LC and Benard G: Anti-TNF- $\alpha$ agents in the treatment of immune-mediated inflammatory diseases: mechanisms of action and pitfalls. Immunotherapy 2: 817-833, 2010.

15. Roach SK and Schorey JS: Differential regulation of the mitogen-activated protein kinases by pathogenic and nonpathogenic mycobacteria. Infect Immun 70: 3040-3052, 2002.

16. Senthil KA, Bansal K, Holla S, Verma-Kumar S, Sharma P and Balaji KN: ESAT-6 induced COX-2 expression involves coordinated interplay between PI3K and MAPK signaling. Mol Immunol 49: 655-663, 2012.

17. Lee SH, Kim DW, Back SS, et al: Transduced Tat-Annexin protein suppresses inflammation-associated gene expression in lipopolysaccharide (LPS)-stimulated Raw 264.7 cells. BMB Rep 44: 484-489, 2011.

18. Zhang W and Liu HT: MAPK signal pathways in the regulation of cell proliferation in mammalian cells. Cell Res 12: 9-18, 2002.

19. Surewicz K, Aung H, Kanost RA, Jones L, Hejal R and Toossi Z: The differential interaction of p38 MAP kinase and tumor necrosis factor-alpha in human alveolar macrophages and monocytes induced by Mycobacterium tuberculois. Cell Immunol 228: 34-41, 2004.

20. Andersson M, Lutay N, Hallgren O, Westergren-Thorsson G, Svensson M and Godaly G: Mycobacterium bovis bacilli Calmette-Guerin regulates leukocyte recruitment by modulating alveolar inflammatory responses. Innate Immun 18: 531-540, 2012.

21. Schlesinger LS, Bellinger-Kawahara CG, Payne NR and Horwitz MA: Phagocytosis of Mycobacterium tuberculosis is mediated by human monocyte complement receptors and complement component C3. J Immunol 144: 2771-2780, 1990.

22. Sánchez A, Espinosa P, García T and Mancilla R: The 19 kDa Mycobacterium tuberculosis lipoprotein $(\mathrm{LpqH})$ induces macrophage apoptosis through extrinsic and intrinsic pathways: a role for the mitochondrial apoptosis-inducing factor. Clin Dev Immunol 2012: 950503, 2012.

23. Brightbill HD, Libraty DH, Krutzik SR, et al: Host defense mechanisms triggered by microbial lipoproteins through toll-like receptors. Science 285: 732-736, 1999.

24. Straus DS and Glass CK: Anti-inflammatory actions of PPAR ligands: new insights on cellular and molecular mechanisms. Trends Immunol 28: 551-558, 2007.

25. Moraes LA, Piqueras L and Bishop-Bailey D: Peroxisome proliferator-activated receptors and inflammation. Pharmacol Ther 110: 371-385, 2006.

26. Mei CL, He P, Cheng B, Liu W, Wang YF and Wan JJ: Chlamydia pneumoniae induces macrophage-derived foam cell formation via PPAR alpha and PPAR gamma-dependent pathways. Cell Biol Int 33: 301-308, 2009.

27. Liu YL, Lu J, Shi J, et al: Increased expression of the peroxisome proliferator-activated receptor gamma in the immune system of weaned pigs after Escherichia coli lipopolysaccharide injection. Vet Immunol Immunopathol 124: 82-92, 2008.

28. Pascual G, Fong AL, Ogawa S, et al: A SUMOylation-dependent pathway mediates transrepression of inflammatory response genes by PPAR-gamma. Nature 437: 759-763, 2005.

29. de Assis EF, Silva AR, Caiado LFC, et al: Synergism between platelet-activating factor-like phospholipids and peroxisome proliferator-activated receptor gamma agonists generated during low density lipoprotein oxidation that induces lipid body formation in leukocytes. J Immunol 171: 2090-2098, 2003. 